\title{
Medical treatment of Rasmussen's Encephalitis: a systematic review
}

Authors: Stanislas LAGARDE ${ }^{1}$, José BOUCRAUT ${ }^{2}$, Fabrice BARTOLOMEI ${ }^{1}$

\section{Affiliations:}

1. Aix Marseille Univ, APHM, INSERM, INS, Inst Neurosci Syst, Timone Hospital, Epileptology Department, Marseille, France

2. Aix Marseille Univ, APHM, INSERM, INS, Inst Neurosci Syst, Conception Hospital, Immunology Laboratory, Marseille, France

Corresponding Author: Dr Stanislas LAGARDE, Stanislas.lagarde@ap-hm.fr , Service Epileptologie et Rythmologie Cérébrale, Hôpital Timone, 264 Rue Saint-Pierre, 13005, Marseille, France 


\begin{abstract}
Rasmussen's encephalitis (RE) is a severe, rare, chronic inflammatory brain disease resulting in drug-resistant epilepsy and progressive destruction of one hemisphere with loss of neurological function. RE is associated with a deterioration of background EEG activity, a progressive atrophy on MRI and an extensive PET hypometabolism over the affected hemisphere. RE is an immune-mediated disease, with a predominant role of CD8+ T cytotoxic cells, microglial cells, and activation of inflammasome pathway. The diagnosis RE is based on clinical (intractable epilepsy and neurological deterioration), electrophysiological (unilateral EEG slowing) and MRI (hemiatrophy) criteria. Antiseizure medications are generally unable to stop seizures. The most effective procedure is hemispherotomy (surgical disconnection of one cerebral hemisphere), but this is associated with permanent motor and neurological deficits. Treatments targeting the immune system are recommended especially in the early stages of the disease or in patients with slow disease progression and mild deficits and/or not eligible for surgery. Based on the pathophysiology, several immunotherapies have been tried in RE (none exhaustively: corticosteroid, IVIG, tacrolimus, azathioprine, adalimumab, mycophenolate mofetil, natalizumab). However, only small cohorts were reported without comparative study. In this review, we will summarise some pathophysiological mechanisms of RE, before reporting the literature data concerning immunotherapies. We then discuss the limitations of these studies and the prospects for further research.
\end{abstract}

Keywords: focal epilepsy, drug resistant epilepsy, Rasmussen Encephalitis, immunotherapy, neuroimmunology 


\section{MAIN BODY}

\section{Introduction}

Rasmussen's encephalitis (RE) is a particularly severe chronic inflammatory brain disease resulting in drug-resistant epilepsy and progressive destruction of one hemisphere. This inflammatory process is accompanied by a progressive loss of neurological function (motor and/or cognitive) in the affected hemisphere [1]. The annual incidence is estimated to be about 2.4 cases/10 millions of people $[1,2]$. The typical form of the disease usually starts in children ( $80 \%$ before the age of 10 years old) and evolves in three stages: a prodromal stage, an acute stage and a residual stage [1,3]. The "prodromal stage" is non-specific with infrequent epileptic seizures and few or no neurological deficit (e.g. mild hemiparesis) or behavioural/cognitive troubles. After a few months, all patients experience an "acute stage" with frequent intractable seizures. During acute stage, patients develop progressive, irreversible neurological deficit (e.g. hemiparesis), and/or cognitive decline and/or behavioural changes. Aphasia can occur if the dominant hemisphere is affected. The "residual stage" is marked by less frequent seizures, but persistent and stable neurological deficits associated with severe intellectual impairment. In $R E$, it is usually observed a deterioration of background EEG activity, a progressive atrophy on MRI and an extensive cerebral hypometabolism (PET-FDG) over the affected hemisphere [1]. Atypical cases have been historically reported with malignant presentation (bilateral form, or very early onset) or a rather slower clinical progression. Thus, about $10 \%$ of RE starts in adolescent and adult patient with slower clinical progression and less severe residual neurological deficit $[1,4]$. 
RE is an immune-mediated disease, featured by consistent $T$ cell involvement [5]. Histological observations of brain tissue of RE patients, showed multifocal areas of cortical inflammation accompanied by perineuronal lymphocytic infiltration (mainly CD8 Lymphocytes T cells) and microglial activation.

The diagnosis of RE is based on clinical (focal seizures and progressive unilateral cortical deficit), electrophysiological (unihemispheric EEG slowing and seizure onset) and morphologic characteristics (unihemispheric atrophy +/- hypersignal), and sometimes on histology showing CD8 Lymphocytes $T$ cells infiltration and microglial activation) [6]. However, using these criteria, early diagnosis is often difficult, which makes it challenging to use immunological treatments at the prodromal stage in order to prevent the occurrence of irreversible neurological damage. RE also may present with atypical signs and symptoms delaying diagnosis. CSF analysis is anormal in most cases but there is no available biomarkers. CSF analysis may show increased proteinorachia or/and increased cell counts [7]. The presence of intrathecal immunoglobulin synthesis is only described for a part of the patient. There is no autoantibody that has been clearly associated with RE (some have been described but with low sensitivity and no specificity). Previous study has also reported increase CSF levels of IgG, CD4+ and CD8+ T cells, granzyme-B, IFN gamma, IL-12 and TNF alpha [7]. However, the alteration of these markers varies according to the stage of the disease and the patient.

Antiseizure medications (ASM) are generally unable to stop seizures. The recommended effective curative treatment is surgery based on hemispherotomy procedures (surgical disconnection of the pathological cerebral hemisphere). The rate of success in term of seizure freedom is high ( $80 \%$ of patients being seizure free) associated with a withdrawal of ASM in many cases $[8,9]$. As a result of this surgery, patients experienced a definitive 
hemiparesis and hemianopia [8,9]. One of the objectives of hemispherotomy is to prevent the severe mental retardation of the residual stage and the timing for surgery remains challenging when dominant hemisphere is involved. This surgery remains however difficult to offer to patients affected by a slowly progressive, non-motor, late onset form of RE [10]. A pharmacological approach with agents acting on the immune system, and in particular on T-cell immunity, is a preferable strategy at an early stage of the disease or in patients with slow disease progression and mild deficits and/or who are not eligible for hemispheric surgery. Based on the pathophysiology, several agents active on the immune system have been proposed in RE (tacrolimus, azathioprine, adalimumab, mycophenolate mofetil, natalizumab, etc ...) [2]. There are few designed clinical trials on the immune approach to RE, essentially on corticosteroids and intravenous immunoglobulin (IVIG), while the evidence for the use of other immune agents is lower, as data are mostly available from case reports and small case series [2].

\section{Pathophysiological mechanisms}

The main pathophysiological hypotheses are summarised in Figure 1.

\subsection{Cellular immunity}

Histological specimens from patient suffering from RE show microglial and lymphocytic nodules and perivascular cuffing, neuronal death, and neuronophagia [11]. Cytotoxic T lymphocytes seem to play a crucial role in RE because most of the inflammatory cells observed are CD3+ T cells especially CD8+ [12] and few CD4+ are observed [5]. About $10 \%$ of these cells are granzyme-B-positive and some are found in close apposition to major histocompatibility complex (MHC) class I positive neurons [12]. CD8+ T cells may also target 
astrocytes in RE [13].This highlights the important role of CD8 T-cell cytotoxicity in the pathogenesis of RE. These CD8 T cells are-resident memory T cells expressing CD103 and CD 69 expanded in the brain of patients with RE [14]. In brain specimens, clonal T-cell expansions is observed supporting the hypothesis of an antigen-driven autoimmune mechanism (in contrast to a random attraction of cells / secondary immune response) [5]. This clonal expansion is also detected in peripheral CD8+ T-cell. T cell receptor (TCR) repertoire analysis thus suggest an antigen-specific expansion of CD8+ lymphocytes against unknown CNS antigens [15]. [16]. A recent study also illustrate the infiltration CD4+ and $\gamma \delta T$ cells in addition to CD8+ T cells[17,18]. CD4+ T cells are also clonally expanded [17]. All 3 populations (CD8+, CD4+ and $\gamma \delta$ ) exhibited a Tc1/Th1 phenotype with production of interferon (IFN)- $\psi$, TNF, interleukin (IL)-5, IL-13, and granzyme B [17].

\subsection{Microglial and inflammasome activation}

In RE, activation of the microglial [11], astrocytes [13] activation and of the inflammasome complex (CASP1, NLRP1, NLRP3) are observed. Activated microglia, via release of proinflammatory cytokines (IL1beta, IL18, TNF $\alpha$ ) [19], may participate in ictogenesis [20]. Analysis of mRNA in brain specimens of patients had also revealed increase of expression of genes involved in activation of helper, inducer, memory and effector $\mathrm{T}$ cells, and in chemokines involved in the recruitment of these lymphocytes T cells (interferon- $\gamma, \mathrm{CCL} 5$, CCL22, CCL23, CXCL9, CXCL10, and Fas ligand) [16]. 


\subsection{Humoral immunity}

The role of B-cells and secreted autoantibodies in RE is more controversial. Several autoantibodies have been found in the serum of patients with RE (anti-GluR3 [21], (Munc)18-1 [22], alpha- 7 nicotinic acetylcholine receptor [23], AMPA receptor[24]). However, these antibodies have been described only in a limited number of patients with RE and could be found in others forms of epilepsy. It has been hypothesized that autoantibodies in RE may be a secondary phenomenon due to the increased availability of antigens, deriving from the neural damage, rather than a primary pathophysiological mechanism.

\subsection{CSF data}

Longitudinal CSF analysis in patients with RE have shown initial increased levels of IgG level, CD4+ and CD8+T cells, TNF- $\alpha$, IFN- $\gamma$, IL-12 and Granzyme B. CD8+ T cells, IFN- $\gamma$ and IL-12 level decline gradually along the progressive stage, whereas production of Granzyme B, TNF- $\alpha$ and CD4+ levels remain elevated [7]. This suggests that crucial cytotoxic process contributes to the pathophysiologic mechanisms during acute stage of the disease and declines in the progressed stage. Moreover, prolonged production of TNF- $\alpha$ leads to elevation of IL-6 that may contribute to the inflammation, inhibition of regulatory T cells, and hyperexcitability $[25,26]$.

\subsection{Experimental data}


Only one study was able to reproduce the histological and clinical features of RE in an experimental murine model. The authors transferred human peripheral blood mononuclear cells (PBMCs) from patients with RE into severe immunodeficient mice (NOD/ LtSz-scid IL$2 R \gamma C$ (null) (NSG)) [27]. In this model, $84 \%$ of the mice had seizures. Moreover, mice transplanted with irradiated PBMC also had seizures (refuting a viral mediation), but not mice receiving plasma excluding the role of humoral factor of the disease. From a histological point of view, the authors observed an infiltration of CD45+ lymphocytes of the patients in close contact with apoptotic neurons suggesting their neuronal cytotoxicity, an astrogliosis and a microglial activation. In addition, the authors tested the effect of two immunotherapies in their model (Figure 2): IVIG and anti-very late antigen-4 (VLA4) blocker (natalizumab), at two times, early (as soon as PBMC transplantation) or late (4 weeks after). Early injection of IVIG decreased seizure occurrence, limited CD45+ cells brain infiltration, altered CD4/CD8 ratio and limited astrogliosis. Early and late injection of anti-VLA4 limited CD45+, CD4+, CD8+ infiltration and the CD4/CD8 ratio. Furthermore, early injection prevented the occurrence of seizures whereas late injection had no such effect on seizures. This suggested that once the disease is established, the reduction of T-cell infiltration in the brain is not sufficient in itself to reduce the frequency of seizures.

Overall, these data support the rationale of immunotherapy in RE, and especially treatment targeting the T-cell immunity. The data suggest a therapeutic windows with higher beneficial potential at the beginning of the disease, when neural and astrocytes damage are limited and brain inflammation could be reverse [28]. However, the persistent T-cell autoimmunity and inflammation observed at latter stage argue for the interest of immunotherapy even at latter stage for slowing the neurological worsening and for an anti-seizure effect (for this 
latter especially treatment targeting pro-ictogenesis cytokines). Figure 1 shows the potential modes of action of immunotherapies in ER.

\section{General principles for the management of Rasmussen's encephalitis}

Anti-seizure medications (ASM) have limited efficacy in Rasmussen's encephalitis. Realistic aims of ASM should be to limit seizure frequency and prevent the most severe seizures with the fewest side- effects. Nowadays, no specific ASM have demonstrated a superior efficacy / tolerability in RE.

Surgery represents the only option to control seizures and stop neurological deterioration in patients with RE [1]. Surgical techniques mainly aim at obtaining a functional disconnection of the affected hemisphere. This has functional consequences because homonymous hemianopia and hemiplegia are inevitable. Recovery of independent walking is expected although fine motor movement in the hand is not. Among surgical procedures of hemispheric disconnection, hemispherotomy techniques exhibits the best results in term of seizure outcome $[29,30]$. The decision of surgery is still however difficult in slow progressive form with limited neurological deficit and /or older children or adult onset in addition when dominant hemisphere is involved. The timing of surgery remains debated. Early surgery may prevent involvement to contralateral normal hemisphere and progressive cognitive deterioration (intellectual decline have been associated with appearance of contralateral epileptic activities) [1]. In case of typical case with seizure onset in children, linguistic abilities are partly supported by the contralateral hemisphere if the surgery is performed before the age of 10 years [9,31,32]. Finally, in adolescent or adult onset, more focal resective surgery could improve seizure outcome in some patients [33]. 
It should be noted that some immunotherapies showed a good anti-seizure effect while others had lesser effect on seizures but could lead to a slowing of functional decline. The latter case may lead to a difficult clinical situation where patients still have disabling epilepsy but with limited neurological deficit, which makes the benefit/risk balance of surgery unfavourable. Furthermore, there appear to be several "windows" of opportunity for the use of immunotherapies:

1) In the very early phase of the disease (prodromal stage) with the objective of blocking the immune/inflammatory process before the onset of refractory epilepsy and the appearance of neurological deficit (nevertheless using the current diagnosis criteria of RE lead to miss this "early therapeutic windows")

2) If the benefit-risk balance is against surgery, particularly in atypical form with slow progressive course and limited neurological deficit, late (adolescent, adult) onset, or in bilateral form

3) In case of worsening of seizures (especially status epilepticus) before possible rescue surgery.

In addition, in patients with a favourable benefit-risk balance for surgery, the trial of immunotherapy should not delay surgery and the effect of immunotherapy should be rapidly evaluated. Figure 3 illustrates the different phases of the disease and the respective indications for surgery and immunotherapies.

\section{Data on medical treatment}

From a methodological point of view, we report also details of studies including previous treatments that may have failed in the reported patients. Indeed, recent case studies 
generally report failure of multiple immunotherapies prior to the trial of the specific immunotherapy covered by the publication. However, we do not report all failures of corticosteroids or IVIG as currently there are no published single cases report of success with these immunotherapies. Incorporating these data runs a high risk of publication bias as by definition only patients with failure of first line immunotherapies are published. In the following, we will first describe the immunotherapies for which there is the most evidence, before those based on case reports/small series.

\subsection{First-Line treatments}

One of the earliest first-line treatments used was high-dose corticosteroids. Corticosteroids act via genomic and non-genomic effects (transcriptional and post-transcriptional mechanisms) with an effect on innate and adaptive immune responses, a reduction in the transcription of several pro-inflammatory genes (mainly IL-1, IL-2, IL-6, TNF- $\alpha$, IL-2R and adhesion molecules), inhibition of antigen-presenting cell (APC) activation and differentiation, increase in T cell apoptosis and shifting of the response from the Th1 to the Th2 phenotype, among others [34,35]. Their long-term use is, moreover, limited by the frequency of side effects, sometimes incapacitating, which lead to premature discontinuation of the treatment; notably: Cushing's syndrome, osteoporosis, hypertension, and infections $[36,37]$. The seminal study by Chinchilla et al. [38], in a paediatric population with epilepsia partialis continua, showed a cessation of the latter in 5 out of 8 patients and an improvement of the latter in the other 3 . In addition, hemiparesis improved in the short term in 5 patients. Hart et al. [39] confirmed efficacy on seizures in $50 \%$ of their patients. In subsequent published series, the efficacy data was favourable with seizure improvement 
rates of $11 / 14$ [40], 9/11 [36], 81\% [37], and $70 \%$ [41]. Overall, about $70 \%(83 / 117)$ of the patients respond initially to corticosteroids (Table 1). However, some studies have suggested a loss of effectiveness in the long term [36] and the rate of long-term side effects/discontinuation of treatment was extremely high in the series [36-39]. Thus, corticosteroids seem to be a very effective treatment in the first line or in case of aggravation of seizure, but they must be followed by another long-term treatment to limit the long-term side effects.

Other studies have reported the use of IVIG as first line or add-on therapy in RE. IVIG acts on both antibody-mediated inflammation (does not appear to be crucial/primary in the pathogenesis of RE) but also via immunomodulation of $T$ cells responses (via inhibition of several co-stimulatory pathways and this may better explain their efficacy in ER) $[42,43]$.

Following case reports reporting efficacy on seizure and neurological outcome [44-47], the use of IVIG have been described in larger series. Granata et al. reported 11 patients (mean age of onset 5.75, disease duration before IVIG 17.8 months) with only three with seizure and motor improvements [40]. Similarly in the study by Takahashi et al., only $23 \%$ of the patients had seizure improvement, $15 \%$ motor improvement and $45 \%$ cognitive stabilisation after IVIG treatment [37]. Pellegrin et al. found higher rate of seizure response(40\%) [41]. Finally, Caraballo et al. reported their experience with a combination of corticosteroids and IVIG in 29 patients with 14 patients (48\%) with seizure response and transient cessation of neurological deterioration [48]. The efficacy of IVIG to reduce seizures (overall $30 \%$ in series of more than 5 patients), appear to be lower compared with corticosteroids (Table 2). It therefore seems logical to propose corticosteroids as the first line of treatment and to reserve immunoglobulins (as a replacement or complement) for cases where corticosteroids 
fail and before starting another long-term treatment. This does not rule out their long-term use on a case-by-case basis, in cases of very good response, because of their better longterm tolerance than corticosteroids (despite the time-consuming nature of their regular administration for the patient).

Following the description of autoantibodies in some patients with RE (even if their secondary role was subsequently suggested), some authors started to use plasmapheresis / immunoadsorption. Plasmapheresis reduces the levels of antibody and other immune mediators and complement fractions. The existing data are mainly from case reports with positive initial effect but recurrence on the long-term [21,49-53]. However, in larger series the rates of seizure response was low $2 / 13$ [40], and 8 others published patients did not respond to plasmapheresis [41,54-59] (Table 3). Notably most of reported responder patients had anti-GluR3 antibodies, questioning a possible pathological side effect of these antibodies. Moreover, the impact on neurological and cognitive deficit were limited. Overall, plasmapheresis has low responders' rates in term of seizure and when effective is associated with recurrence on the long-term. Thus, in our view it could be proposed in patients with high seizure burden and inefficacy of other first line treatment (corticosteroid, IgIV) before a rapid relay to another long-term immunotherapy.

\subsection{Treatments targeting lymphocytes}

One of the first treatments specifically targeting lymphocytes studied was tacrolimus. Tacrolimus has an anti-calcineurin effect with inhibition of the T-cell immune response, including a decrease in IL-2 cytokine production and T- and NK-cell activation. However, it has shown low effectiveness on seizures in some series $[60,61]$, and better in another one 
with $42 \%$ of responders in the cohort of Takahashi et al. [37]. However, it slowed down neurological worsening and progressive MRI atrophy compared to an untreated historical cohort $[60,61]$. Takahashi et al. reported $75 \%$ cognitive stabilisation and $8 \%$ motor improvement in their series. It should be noted, however, that compared to IVIG treatment, the use of tacrolimus was associated with a comparable clinical response, but also with a higher rate of adverse events [61]. Finally, in other case reports, 3 patients did not respond to tacrolimus $[52,62,63]$ (Table 4). Thus, the value of using tacrolimus seems limited in clinical practice as it may lead to patients with still drug-resistant/disabling epilepsy but with a slowing of neurological decline that unbalances the benefit/risk balance of anti-epileptic surgery. There may be a potential niche use for patients with mainly neurological decline and less disabling seizures. The question could also arise of using it as a complement to a more effective treatment for seizures.

Azathioprine is an inhibitor of purine synthesis that results in decreased T-cell proliferation and apoptosis of activated T-cells. Only one retrospective study has reported its use in a paediatric cohort of 53 children with RE (median time from disease onset to commencing azathioprine was 2.8 years), as a relay to initial corticosteroid therapy [41]. $89 \%$ of patients showed a sustained seizure response (Table 4). Compared to the non-azathioprine group, the azathioprine-treated group had a longer time to the onset of epilepsia partialis continua, hemiparesis and to the performance of hemispherotomy. Nevertheless, in the end, $25 / 30$ patients treated with azathioprine developed hemiparesis versus 20/23 without azathioprine; and 19/30 patients treated with azathioprine developed epilepsia partialis continua versus $20 / 23$ without azathioprine. Furthermore, there was no significant effect on 
the progression of grey matter atrophy on MRI, nor on the cognitive evolution. In case reports / other series, $\mathrm{n}=4$ patients did not respond to azathioprine [15,64-67].

Thus, azathioprine seems to have an interesting effect on the control of seizures but less marked on the progression of the disease (neurological and cognitive deficits, MRI).

Mycophenolate mofetil acts by inhibiting purine synthesis in lymphocytes, inducing apoptosis of activated Lymphocytes T-cells and reducing the recruitment of lymphocytes. Only case reports exist: one with cessation of seizures and neurological deterioration after an early use in combination with cyclophosphamide [28], another with cessation of neurological deterioration (patient without seizure in his history) [68] and one last with a decrease in seizure frequency and neurological improvement [69] (Table 4). There are two other case reports with no reported efficacy $[52,62]$.

Rituximab has also been tested in RE. Although the pathophysiological rationale of rituximab does not seem obvious at first glance due to its anti-CD20 / B-cell effect (whereas inflammation in RE is mainly T-cell mediated), it is noteworthy that B-cells have also a role in T-cell activation through their antigen-presenting and cytokine-producing activities. Rituximab may, thus, act as an indirect anti-T-cell treatment [70]. Some case reports have suggested a beneficial effect ( $n=3$ patients): cessation of status epilepticus [54], improvement in the frequency and severity of seizures and in walking and language skills [71], improvement of seizure severity [52] ; but others have either found only a transient effect $(n=1)$ [52] or no effect at all $(n=5)[15,53,55,56,62,64]$. One study reported no change in TCR diversity under treatmentafter rituximab [15]. Only one poster, to date not properly published with subsequent peer-reviewing, reported the use of rituximab in 9 patients with 
improvement of seizures in 8 patients, of which 3 were seizure-free, and neurological improvement or stabilisation in 8 patients (median follow-up was 10 months) [72]. Thus, the data are still inconsistent to give a conclusive statement on its indication (Table 5).

\subsection{Treatments targeting pro-inflammatory cytokines}

A first study have reported efficacy of infliximab in a particular form of Rasmussen's Syndrome associated with granulomatosis [73]. Following evidences of increase level of TNF$\alpha$ in $\operatorname{RE}[7,17]$ and its involvement in ictogenesis $[25,26]$, we also start to use anti-TNF- $\alpha$ (adalimumab) in patients with RE. We studied eleven patients (mean age of onset 6.5 years, mean disease duration before treatment 31 months) without efficacy of previous immunotherapies and without surgical possibility [65]. We found 5/11 patients' responders in term of seizure and 3 of these 5 with cognitive stability and motor improvement (Table 6). Long-term follow-up showed good tolerance. Notably the efficacy seems better in patients with late onset / slowly progressive disease. These results were encouraging because of the favourable effect on seizure and could be explain by the important role of TNF- $\alpha$ both in inflammation and hyperexcitability even at the progressed stage of the disease. This treatment could be proposed to patients with a slow form of RE and/or a surgical nonindication. Knowing that in the Takahashi et al. study there seemed to be two populations in terms of CSF TNF- $\alpha$ levels (one with high levels and one without) [7], the question arises of adapting the choice of anti-TNF- $\alpha$ treatment to the level of TNF- $\alpha$ in the CSF. A French observational register of the use of anti-TNF- $\alpha$ in RE is currently being compiled (https://clinicaltrials.gov/ct2/show/NCT04003922). 
Anakinra is a recombinant and slightly modified form interleukin-1(IL-1) receptor antagonist (IL-1Ra) that blocks the inflammatory activity of both IL-1 $\alpha$ and IL-1 3 . Their receptors are expressed both in neurons and glial cells. Moreover, IL-1ß has ictogenic properties in various seizure models $[74,75]$ and IL-1 receptor antagonists have been shown antiseizure effect in mice [76-78]. Anakinra have also shown some positive effect in cases of NORSE/FIRES [79]. A case report on the use of anakinra in a patient with RE, 28 years after clinical onset, showed a complete cessation of seizures for a period of 13 months without recurrence [80] (table 6). Like anti-TNF- $\alpha$, anti-IL1 treatment seems to be of interest because of its anti-seizure in addition to its anti-inflammatory properties. Future studies are needed to confirm/infirm their interest in RE.

\subsection{Others}

Natalizumab is an anti-CD49 antibody, which acts by inhibiting the migration of immune cells across the blood-brain barrier. Its efficacy has been well demonstrated in multiple sclerosis. From a pathophysiological point of view, its use in RE seems interesting, particularly in the early phase of the disease, in order to avoid the invasion of the brain by Lymphocytes $T$. One patient was reported to have stopped the epilepsia partialis continua and to have gone from 5-10 seizures per day to 1 seizure per day, his neurological course was not described $[15,64]$. After treatment, the number of unique clonotypes increased markedly, consistent with sequestering effect of natalizumab (putatively pathogenic clones were not depleted, but most probably restricted to the peripheral compartment) and no change in TCR diversity was observed [15]. However, it should be noted that natalizumab was used in this case 16 
years after the onset of the disease and therefore far from the acute phase. Another case report did not find efficacy of natalizumab [59]. Liba et al. also reported that in a patient without clinical efficacy of natalizumab and who underwent hemispherotomy, the inflammatory load and T-cell infiltration in the brain tissue was lower than with other immunotherapy (cyclophosphamide) [81] (Table 7). In view of the experimental data in mice (efficacy if used early, ineffectiveness once the acute phase has passed) [27], it would seem useful to study its efficacy in the very early phase of the disease.

Cyclophosphamide is an alkylating agent with immunosuppressive effect. 7 cases of its use have been described in the literature. Krauss et al. reported a case of clinical stabilisation for 6 months with recurrence and the need for further immunotherapy [82]. Liba et al. reported a case of efficacy of an early immunotherapy protocol (start 1 month after diagnosis) combining corticosteroids + cyclophosphamide with relay by mycophenolate mofetil (follow-up over 15 months) [28]. However, the 5 other published cases did not show any efficacy $[40,54,57-59]$ (Table 7$)$. Thus, clinical data in RE are limited, and cumulative toxicity does not seem to favour its use in the long-term treatment of RE

Mitoxantrone is an anthracenedione derivative leading to inhibition of Lymphocytes B, Lymphocytes $\mathrm{T}$ and macrophage proliferation, inhibition of antigen presentation and inhibition of release of cytokines such as IFN- - and TNF- $\alpha$. One study [57] reports two cases of adult-onset RE with discontinuation of epilepsia partialis continua and decrease in seizure frequency (from weekly to monthly) (Table 7). One of the two cases also showed an improvement in language. It should be noted that like cyclophosphamide, the existence of a maximum cumulative dose may hamper the long-term use of this molecule in RE. 
Alemtuzumab is a monoclonal antibody targeting CD52 that leads to long-term depletion of lymphocytes. Liba et al. reported its use in combination with regular intrathecal methotrexate injections and mycophenolate mofetil. In their patient they observed an transitory improvement in seizures and neurological status but with rapid re-aggravation requiring regular repeat intrathecal injections of methotrexate leading to a severe systemic reaction and hyperpyrexia needing with admission to ICU [62]. Finally, patient require hemispherotomy. However, the patient was treated lately after the onset of the disease. Noteworthy, they observed strong lymphocyte depression in blood and CSF not correlated to the clinical effect. The histological analysis reveal a low percentage of activated cytotoxic T cells and limited inflammatory changes [81].

Anecdotally, early ganciclovir has been reported to be effective in $1 / 3$ patients with atypical $\mathrm{RE}$ (the majority not meeting the diagnosis criteria)[83,84]. Another reported patient did not respond to ganciclovir [66]. The rationale being the presence of the CMV genome in the brain tissue of some patients with RE. One study reported transitory efficacy of zidovudine, an antiretroviral used in HIV infection [85]. Three patients have also been reported following the use of intraventricular interferon $\alpha$ without prolonged efficacy $[66,86,87]$. One case report concerned thalidomide with modest effect on seizure [88]. Ciclosporin was not found efficacious in one patient [66]. More recently, Schneider at al. reported the clinical failure of the basilixumab (a monoclonal antibody directed against the interleukin-2 receptor $\alpha$ chain CD25, $n=1$ ) without change in TCR diversity [15] ; and of stem cell transplantation despite the replacement of TCR repertoire [15]. Finally, Szczepanik et al. reported the use of intrathecal infusion of autologous adipose-derived regenerative cells in two patients with 
RE: one without efficacy and another with only transitory seizure frequency improvement [89].

\section{Discussion / Perspectives}

In this review we report the existing data concerning the medical treatment of RE (Figure 4). Because of the rarity of the disease, the level of evidence of most studies is rather low because their design is open, and they are often case studies with low numbers.

Two types of treatment can be distinguished: 1) first-line treatments which have a rapid but mostly transient effect and can therefore be used either as a first-line treatment before a relay by another immunotherapy, or in case of rapid worsening of the disease; 2) second-line treatments which have a longer duration of action with a better tolerance in the long term. Regarding first-line treatments, the most important data concerns corticosteroids with more than 100 patients reported. Moreover, their efficacy rate on seizures is higher than the other two first-line treatments: IVIG and plasmapheresis. Their efficacy seems to exist both in the form of intravenous boluses and with per os use. They may also provide motor improvement, but it is difficult to distinguish between an improvement secondary to the reduction in seizure frequency or an intrinsic effect on neurological status. However, the effect of corticosteroids is mostly transient, and their long-term use is associated with frequent side effects. This explains the need for a relay with another immunotherapy. In patients with lack of efficacy, or insufficient efficacy or contraindication to corticosteroids, IVIG and/or plasmapheresis can also be used, sometimes with beneficial effect. Finally, there 
are no prospective comparative studies that have compared the effect of these three therapies. Some studies have suggested the value of having a first line treatment as early as possible in order to limit the initial inflammation. This is also supported by an experimental study in mice [27] where the early use of IVIG or natalizumab (which blocks the passage of lymphocytes through the blood brain barrier) showed good efficacy, in contrast to their delayed use. From a pathophysiological point of view the use of natalizumab at this stage of the disease seems interesting but very few clinical cases have been reported $[15,59,64,81]$. A pitfall of this early treatment is the sometimes long diagnostic delay in this disease due to the clinical criteria which include atrophy and neurological deficit which may appear relatively late in the course of the disease. It appears therefore crucial to search for biomarkers (notably in the blood and CSF of patients, probably multimodal analyses of lymphocyte populations and inflammasome) early in the disease in order to be able to initiate treatment from the very early phase of the disease.

For second line treatments the existing literature is more limited with many case reports and a few larger series. The maximum amount of data is available, in decreasing order, for azathioprine $(n=34)$, tacrolimus $(n=31)$, rituximab (19), cyclophosphamide and adalimumab ( $n=11$ each). However, it should be noted that the data for rituximab is mainly from a poster from 2008 [72] without a corresponding peer-reviewed publication. Most of these therapies target $\mathrm{T}$ cells either directly or indirectly (e.g. rituximab). It should be noted at the outset that cyclophosphamide appears to be of limited efficacy and poses the problem of its longterm use due to its cumulative toxicity. In addition, tacrolimus has only a limited effect on the seizures but could have a slowing effect on the atrophy/motor deficit progression. This may paradoxically complicate the management of patients under tacrolimus as it limits the indication of hemispherotomy. Its place could be in forms of the disease with less 
troublesome/invalidating seizures or as an adjunct to other treatments. Seizure efficacy data for azathioprine, rituximab and adalimumab seem more encouraging. Azathioprine resulted in about $70 \%$ seizure response, rituximab in about $60 \%$ and adalimumab in almost $50 \%$. It should be noted that the efficacy of azathioprine came from an exclusively paediatric series and that adalimumab seemed to have a more marked effect in late onset and slow progression forms. It is also worth noting that azathioprine had little effect on neurological decline. The data seem more encouraging for rituximab and adalimumab but need to be consolidated in larger series. On the same pathophysiological rationale, some data are available on mycophenolate mofetil, which is sometimes better tolerated than azathioprine, and will need to be complemented by future studies. Amongst second line treatments, some have experimentally demonstrated an intrinsic anti-seizure and anti-epileptogenic effect (anti-TNF- $\alpha$ and anti-IL-1) and future studies of these treatments in more patients with RE would be interesting. Some other treatments targeting lymphocytes (fingolimob, clabidrin) or microglial activation (cyclin, perindopril) have been suggested but not studied in Rasmussen's encephalitis [1].

The choice of the second line of treatment should take into account: 1) the characteristics of RE (severity of epilepsy versus rapidity of neurological progression, adult versus child onset), 2) contraindications, 3) comorbidities, particularly autoimmune, and 4) discussion with the patient on the methods of administration. In the future, it would seem useful to be able to correlate the effectiveness of the treatment with a certain number of biomarkers that can be measured in the blood and CSF of patients. For example, in some studies, there appear to be two groups in terms of the level of TNF- $\alpha$ in the CSF. One could thus imagine selecting patients eligible for treatment with adalimumab or anakinra according to the levels of TNF$\alpha$, IL-1 $\alpha$ or IL-1 $\beta$ in the CSF respectively. Finally, the use of a combination of second-line 
treatments could be envisaged in order to have a dual effect of anti-T cell and proinflammatory cytokine.

Our review is of course limited by the lack of comparative studies, the high variability of patients with RE, the low number of patients per series and efficacy criteria that are sometimes not very detailed or different from one study to another. Another important bias, especially for case reports, is publication bias. In this context, it seems crucial to be able to report data from a large-scale multicentre registry to obtain efficacy and safety profiles of immunotherapies and a protocolised evaluation of the response to treatment. Furthermore, the analysis of clinical profiles of responses to treatment and correlations between immunological markers and efficacy would allow a step towards personalised medicine.

\section{Conclusion}

The medical treatment of RE is based on anti-inflammatory/immunomodulatory treatments. These should not delay hemispherotomy when indicated because of a possible better effect and better cognitive outcome when perform at an earlier stage. Immunotherapies are however interesting at an early stage of the disease or in case of contraindication/nonindication to hemispherotomy (slow form, without marked neurological deficit, affecting the dominant hemisphere, late onset). There is no comparative study of immunotherapies. As a first line treatment, corticosteroids (IV or oral) appear to be the most effective. They can be supplemented with IVIG if necessary. In relay/second line, the most robust efficacy data concern azathioprine, adalimumab and rituximab. Tacrolimus has little effect on seizures although it slows the progression of atrophy. Finally, some treatments with an interesting 
pathophysiological rationale (natalizumab, anakinra, mycophenolate mofetil) require further studies in the future.

\section{Declaration of interest:}

The authors declare no conflict of interest.

\section{REFERENCES}

[1] Varadkar S, Bien CG, Kruse CA, Jensen FE, Bauer J, Pardo CA, et al. Rasmussen's encephalitis: Clinical features, pathobiology, and treatment advances. Lancet Neurol 2014;13:195-205. https://doi.org/10.1016/S1474-4422(13)70260-6.

[2] Orsini A, Foiadelli T, Carli N, Costagliola G, Masini B, Bonuccelli A, et al. Rasmussen 's encephalitis : From immune pathogenesis towards targeted- therapy. Seizure Eur J Epilepsy 2020;81:76-83.

[3] Bien CG. The natural history of Rasmussen's encephalitis. Brain 2002;125:1751-9. https://doi.org/10.1093/brain/awf176.

[4] Dupont S, Gales A, Sammey S, Vidailhet M, Lambrecq V. Late-onset Rasmussen Encephalitis: A literature appraisal. Autoimmun Rev 2017;16:803-10. https://doi.org/10.1016/j.autrev.2017.05.022.

[5] Schwab N, Bien CG, Waschbisch A, Becker A, Vince GH, Dornmair K, et al. CD8+ T-cell clones dominate brain infiltrates in Rasmussen encephalitis and persist in the periphery. Brain 2009;132:1236-46. https://doi.org/10.1093/brain/awp003.

[6] Bien CG, Granata T, Antozzi C, Cross JH, Dulac O, Kurthen M, et al. Pathogenesis, diagnosis and treatment of Rasmussen encephalitis: A European consensus statement. Brain 2005;128:454-71. https://doi.org/10.1093/brain/awh415.

[7] Takahashi Y, Mine J, Kubota Y, Yamazaki E, Fujiwara T. A substantial number of Rasmussen syndrome patients have increased IgG, CD4+ T cells, TNF $\alpha$, and Granzyme B in CSF. Epilepsia 2009;50:1419-31. https://doi.org/10.1111/j.15281167.2008.01977.x.

[8] Cross JH, Jayakar P, Nordli D, Delalande O, Duchowny M, Wieser HG, et al. Proposed criteria for referral and evaluation of children for epilepsy surgery: Recommendations of the subcommission for pediatric epilepsy surgery. Epilepsia 2006;47:952-9. https://doi.org/10.1111/j.1528-1167.2006.00569.x.

[9] Bulteau C, Grosmaitre C, Save-Pédebos J, Leunen D, Delalande O, Dorfmüller G, et al. Language recovery after left hemispherotomy for Rasmussen encephalitis. Epilepsy 
Behav 2015;53:51-7. https://doi.org/10.1016/j.yebeh.2015.07.044.

[10] Harris WB, Westley Phillips H, Chen JS, Weil AG, Ibrahim GM, Fallah A. Seizure outcomes in children with Rasmussen's encephalitis undergoing resective or hemispheric epilepsy surgery: An individual participant data meta-analysis. J Neurosurg Pediatr 2020;25:274-83. https://doi.org/10.3171/2019.9.PEDS19380.

[11] Pardo CA, Vining EPG, Guo L, Skolasky RL, Carson BS, Freeman JM. The Pathology of Rasmussen Syndrome: Stages of Cortical Involvement and Neuropathological Studies in 45 Hemispherectomies. Epilepsia 2004;45:516-26. https://doi.org/10.1111/J.00139580.2004.33103.X.

[12] Bien CG, Bauer J, Deckwerth TL, Wiendl H, Deckert M, Wiestler OD, et al. Destruction of neurons by cytotoxic T cells: A new pathogenic mechanism in Rasmussen's encephalitis. Ann Neurol 2002;51:311-8. https://doi.org/10.1002/ana.10100.

[13] Bauer J, Elger CE, Hans VH, Schramm J, Urbach H, Lassmann H, et al. Astrocytes are a specific immunological target in Rasmussen's encephalitis. Ann Neurol 2007;62:6780. https://doi.org/10.1002/ana.21148.

[14] Owens GC, Chang JW, Huynh MN, Chirwa T, Vinters H V., Mathern GW. Evidence for resident memory T cells in Rasmussen encephalitis. Front Immunol 2016;7:1-7. https://doi.org/10.3389/fimmu.2016.00064.

[15] Schneider-Hohendorf T, Mohan H, Bien CG, Breuer J, Becker A, Görlich D, et al. CD8 + $T$-cell pathogenicity in Rasmussen encephalitis elucidated by large-scale T-cell receptor sequencing. Nat Commun 2016;7:11153. https://doi.org/10.1038/ncomms11153.

[16] Owens GC, Huynh MN, Chang JW, McArthur DL, Hickey MJ, Vinters H V., et al. Differential expression of interferon- $\gamma$ and chemokine genes distinguishes Rasmussen encephalitis from cortical dysplasia and provides evidence for an early Th1 immune response. J Neuroinflammation 2013;10:1-13. https://doi.org/10.1186/1742-209410-56.

[17] Al Nimer F, Jelcic I, Kempf C, Pieper T, Budka H, Sospedra M, et al. Phenotypic and functional complexity of brain-infiltrating $T$ cells in Rasmussen encephalitis. Neurol Neuroimmunol Neurolnflammation 2018;5. https://doi.org/10.1212/NXI.0000000000000419.

[18] Owens GC, Erickson KL, Malone CC, Pan C, Huynh MN, Chang JW, et al. Evidence for the involvement of gamma delta $T$ cells in the immune response in Rasmussen encephalitis. J Neuroinflammation 2015;12. https://doi.org/10.1186/s12974-0150352-2.

[19] Ramaswamy V, Walsh JG, Sinclair DB, Johnson E, Tang-Wai R, Wheatley BM, et al. Inflammasome induction in Rasmussen's encephalitis: cortical and associated white matter pathogenesis. J Neuroinflammation 2013;10:918. https://doi.org/10.1186/1742-2094-10-152.

[20] Vezzani A, French J, Bartfai T, Baram TZ. The role of inflammation in epilepsy. Nat Rev Neurol 2011;7:31-40. https://doi.org/10.1038/nrneurol.2010.178.

[21] Rogers SW, Andrews PI, Gahring LC, Whisenand T, Cauley K, Crain B, et al. Autoantibodies to glutamate receptor GluR3 in Rasmussen's encephalitis. Science (80) 1994;265:648-51. https://doi.org/10.1126/science.8036512.

[22] Yang R, Puranam RS, Butler LS, Qian WH, He XP, Moyer MB, et al. Autoimmunity to Munc-18 in Rasmussen's encephalitis. Neuron 2000;28:375-83.

https://doi.org/10.1016/S0896-6273(00)00118-5. 
[23] Watson R, Jepson JEC, Bermudez I, Alexander S, Hart Y, McKnight K, et al. $\alpha 7$ Acetylcholine receptor antibodies in two patients with Rasmussen encephalitis. Neurology 2005;65:1802-4. https://doi.org/10.1212/01.WNL.0000191566.86977.04.

[24] Nibber A, Clover L, Pettingill P, Waters P, Elger CE, Bien CG, et al. Antibodies to AMPA receptors in Rasmussen's encephalitis. Eur J Paediatr Neurol 2016;20:222-7. https://doi.org/10.1016/j.ejpn.2015.12.011.

[25] Bernardino L, Xapelli S, Silva AP, Jakobsen B, Poulsen FR, Oliveira CR, et al. Modulator effects of interleukin-1 $\beta$ and tumor necrosis factor- $\alpha$ on AMPA-induced excitotoxicity in mouse organotypic hippocampal slice cultures. J Neurosci 2005;25:6734-44. https://doi.org/10.1523/JNEUROSCI.1510-05.2005.

[26] Stellwagen D, Beattie EC, Seo JY, Malenka RC. Differential regulation of AMPA receptor and GABA receptor trafficking by tumor necrosis factor- $\alpha$. J Neurosci 2005;25:3219-28. https://doi.org/10.1523/JNEUROSCI.4486-04.2005.

[27] Kebir H, Carmant L, Fontaine F, Béland K, Bosoi CM, Sanon NT, et al. Humanized mouse model of Rasmussen's encephalitis supports the immune-mediated hypothesis. J Clin Invest 2018;128:2000-9. https://doi.org/10.1172/JCI97098.

[28] Liba Z, Muthaffar O, Tang J, Minassian B, Halliday W, Branson H, et al. Rasmussen encephalitis: Response to early immunotherapy in a case of immune-mediated encephalitis. Neurol Neuroimmunol Neurolnflammation 2015;2:e69. https://doi.org/10.1212/NXI.0000000000000069.

[29] Fallah A, Lewis E, Ibrahim M, Kola O, Tseng H, Harris B, et al. Comparison-of-the-real-world-effectiveness-of-verticalversus-lateral-functional-hemispherotomy-techniques-for-pediatric-drug-resistant-epilepsy:-A-post-hoc-analysis-of-the- HOPS-study 2021. https://doi.org/10.1111/epi.17021.

[30] Bourdillon P, Bulteau C, Dorfmüller G, Ferrand-Sorbets S. Vertical hemispherotomy for drug-resistant epilepsy: Toward confirmation of the HOPS study. Epilepsia 2021;62:3150-1. https://doi.org/10.1111/epi.17111.

[31] Boatman D, Freeman J, Vining E, Pulsifer M, Miglioretti D, Minahan R, et al. Language recovery after left hemispherectomy in children with late-onset seizures. Ann Neurol 1999;46:579-86. https://doi.org/10.1002/1531-8249(199910)46:4<579::aidana5>3.0.co;2-k.

[32] Hertz-Pannier L, Chiron C, Jambaque I, Renaux-Kieffer V, Van De Moortele PF, Delalande $\mathrm{O}$, et al. Late plasticity for language in a child's non-dominant hemisphere: a pre- and post-surgery fMRI study. Brain 2002;125:361-72. https://doi.org/10.1093/BRAIN/AWF020.

[33] Casciato S, Di Bonaventura C, Giallonardo AT, Fattouch J, Quarato PP, Mascia A, et al. Epilepsy surgery in adult-onset Rasmussen's encephalitis: case series and review of the literature. Neurosurg Rev 2015;38:463-71. https://doi.org/10.1007/s10143-0150623-5.

[34] Vandewalle J, Luypaert A, De Bosscher K, Libert C. Therapeutic Mechanisms of Glucocorticoids. Trends Endocrinol Metab 2018;29:42-54. https://doi.org/10.1016/j.tem.2017.10.010.

[35] T R, JA C. Antiinflammatory action of glucocorticoids--new mechanisms for old drugs. N Engl J Med 2005;353:1711-23. https://doi.org/10.1056/NEJMRA050541.

[36] Bahi-Buisson N, Villanueva V, Bulteau C, Delalande O, Dulac O, Chiron C, et al. Long term response to steroid therapy in Rasmussen encephalitis. Seizure 2007;16:485-92. 
https://doi.org/10.1016/j.seizure.2007.03.002.

[37] Takahashi Y, Yamazaki E, Mine J, Kubota Y, Imai K, Mogami Y, et al. Immunomodulatory therapy versus surgery for Rasmussen syndrome in early childhood. Brain Dev 2013;35:778-85. https://doi.org/10.1016/j.braindev.2013.01.010.

[38] Chinchilla D, Dulac O, Robain O, Plouin P, Ponsot G, Pinel JF, et al. Reappraisal of Rasmussen's syndrome with special emphasis on treatment with high doses of steroids. J Neurol Neurosurg Psychiatry 1994;57:1325-33. https://doi.org/10.1136/jnnp.57.11.1325.

[39] Hart YM, Cortez M, Andermann F, Hwang P, Fish DR, Dulac O, et al. Medical treatment of rasmussen's syndrome (chronic encephalitis and epilepsy: Effect of high)dose steroids or immunoglobulins in 19 patients. Neurology 1994;44:1030-6. https://doi.org/10.1212/wnl.44.6.1030.

[40] Granata T, Fusco L, Gobbi G, Freri E, Ragona F, Broggi G, et al. Experience with immunomodulatory treatments in Rasmussen's encephalitis. Neurology 2003;61:1807-10. https://doi.org/10.1212/WNL.63.9.1761-a.

[41] Pellegrin S, Baldeweg T, Pujar S, D’Arco F, Cantalupo G, Varadkar S, et al. Immunomodulation with Azathioprine therapy in Rasmussen syndrome: A multimodal evaluation. Neurology 2020;96:10.1212/WNL.0000000000011004. https://doi.org/10.1212/wnl.0000000000011004.

[42] Nimmerjahn F, Ravetch J V. The antiinflammatory activity of IgG: The intravenous IgG paradox. J Exp Med 2007;204:11-5. https://doi.org/10.1084/jem.20061788.

[43] Lünemann JD, Nimmerjahn F, Dalakas MC. Intravenous immunoglobulin in neurology-mode of action and clinical efficacy. Nat Rev Neurol 2015;11:80-9. https://doi.org/10.1038/nrneurol.2014.253.

[44] Wise MS, Rutledge SL, Kuzniecky RI. Rasmussen Syndrome and Long-Term Response to Gamma Globulin. Pediatr Neurol 1996;14:149-52.

[45] Leach JP, Chadwick DW, Miles JB, Hart IK. Improvement in adult-onset Rasmussen's encephalitis with long-term immunomodulatory therapy. Neurology 1999;52:738-42. https://doi.org/10.1212/wnl.52.4.738.

[46] Villani F, Spreafico R, Farina L, Giovagnoli AR, Bernasconi P, Granata T, et al. Positive response to immunomodulatory therapy in a adult patient with Rasmussen's encephalitis. Neurology 2001;56:248-50. https://doi.org/10.1212/WNL.56.2.248.

[47] P. W. Treatment of Rasmussen's syndrome with intra- venous gammaglobulin. Chronic Enceph. epilepsy Rasm. Syndr., 1991, p. 204-4.

[48] Caraballo RH, Fortini S, Cersósimo R, Monges S, Pasteris MC, Gomez M, et al. Rasmussen syndrome: An Argentinean experience in 32 patients. Seizure 2013;22:360-7. https://doi.org/10.1016/j.seizure.2013.02.003.

[49] Andrews PI, Dichter MA, Berkovic SF, Newton MR, McNamara JO. Plasmapheresis in Rasmussen's encephalitis. Neurology 1996;46:242-6. https://doi.org/10.1212/WNL.46.1.242.

[50] Palcoux J, Tardieu M, Carpentier C, Sebire G, Garcier J, Loriette Y, et al. Plasma Exchange in Rasmussen's Encephalitis. Ther Apher 1997;1:79-82.

[51] Antozzi C, Granata T, Aurisano N, Zardini G, Confalonieri P, Airaghi G, et al. Long-term selective IgG immunoadsorption improves Rasmussen's encephalitis. Neurology 1998;51:302-5. https://doi.org/10.1212/WNL.51.1.302.

[52] Thilo B, Stingele R, Knudsen K, Boor R, Bien CG, Deuschl G, et al. A case of Rasmussen 
encephalitis treated with rituximab. Nat Rev Neurol 2009;5:458-62.

https://doi.org/10.1038/nrneurol.2009.98.

[53] Cantarín-Extremera V, Jiménez-Legido $M$, Sebastián-Pérez E, Duat-Rodríguez A, Ruiz-

Falcó Rojas ML. Inmunoadsorción y plasmaféresis: ¿posibilidades de tratamiento en la encefalitis de Rasmussen? Rev Neurol 2020;70:159-60.

https://doi.org/10.33588/rn.7004.2019439.

[54] Timárová G, Lisá I, Kukumberg P. Long-term effect of rituximab in a case with Lateonset Rasmussen's encephalitis with anti-ganglioside IgGQlb and anti-GAD antibodies positivity. Neuroendocrinol Lett 2016;37:179-83.

[55] Castellano JF, Meyer JA, Lado FA. A Case Series of Adult-Onset Rasmussen's Encephalitis: Diagnostic and Therapeutic Challenges. Front Neurol 2017;8:1-7. https://doi.org/10.3389/fneur.2017.00564.

[56] Sansevere AJ, Henderson LA, Stredny CM, Prabhu SP, Shah A, Sundel R, et al. Posterior-onset Rasmussen's encephalitis with ipsilateral cerebellar atrophy and uveitis resistant to rituximab. Epilepsy Behav Reports 2020;14:100360. https://doi.org/10.1016/j.ebr.2020.100360.

[57] Stabile A, Deleo F, Didato G, Pastori C, Antozzi C, Curtis M de, et al. Adult-onset Rasmussen encephalitis treated with mitoxantrone. Eur J Neurol 2018;25:e125-6. https://doi.org/10.1111/ENE.13795.

[58] Amrom D, Kinay D, Hart Y, Berkovic SF, Laxer K, Andermann F, et al. Rasmussen encephalitis and comorbid autoimmune diseases: A window into disease mechanism? Neurology 2014;83:1049-55. https://doi.org/10.1212/WNL.0000000000000791.

[59] Soh D, Cordato DJ, Bleasel AF, Brimage P, Beran RG. Can head trauma trigger adultonset Rasmussen 's encephalitis ? Epilepsy Behav 2017;74:119-23. https://doi.org/10.1016/j.yebeh.2017.06.027.

[60] Bien CG, Gleissner U, Sassen R, Widman G, Urbach H, Elger CE. An open study of tacrolimus therapy in Rasmussen encephalitis. Neurology 2004;62:2106-9. https://doi.org/10.1212/01.WNL.0000128044.94294.87.

[61] Bien CG, Tiemeier H, Sassen R, Kuczaty S, Urbach H, Von Lehe M, et al. Rasmussen encephalitis: Incidence and course under randomized therapy with tacrolimus or intravenous immunoglobulins. Epilepsia 2013;54:543-50. https://doi.org/10.1111/epi.12042.

[62] Liba Z, Sedlacek P, Sebronova V, Maulisova A, Rydenhag B, Zamecnik J, et al. Alemtuzumab and intrathecal methotrexate failed in the therapy of Rasmussen encephalitis. Neurol Neuroimmunol NeuroInflammation 2017;4. https://doi.org/10.1212/NXI.0000000000000354.

[63] Terra-Bustamante VC, MacHado HR, Dos Santos Oliveira R, Serafini LN, Souza-Oliveira $C$, Escorsi-Rosset $\mathrm{S}$, et al. Rasmussen encephalitis: Long-term outcome after surgery. Child's Nerv Syst 2009;25:583-9. https://doi.org/10.1007/s00381-008-0795-1.

[64] Bittner S, Simon OJ, Gobel K, Bien CG, Meuth SG, Wiendl H. Rasmussen encephalitis treated with natalizumab. Neurology 2013;81:395-7. https://doi.org/10.1212/wnl.0b013e31829c5ceb.

[65] Lagarde S, Villeneuve N, Trébuchon A, Kaphan E, Lepine A, McGonigal A, et al. Antitumor necrosis factor alpha therapy (adalimumab) in Rasmussen's encephalitis: An open pilot study. Epilepsia 2016;57:956-66. https://doi.org/10.1111/epi.13387.

[66] Muto A, Oguni H, Takahashi Y, Shirasaka Y, Sawaishi Y, Yano T, et al. Nationwide survey (incidence, clinical course, prognosis) of Rasmussen's encephalitis. Brain Dev 
2010;32:445-53. https://doi.org/10.1016/j.braindev.2009.10.004.

[67] Klaa H, Ben Younes T, Benrhouma H, Nagi S, Rouissi A, Kraoua I, et al. Rasmussen's Encephalitis: A Report of a Tunisian Pediatric Case and Literature Review. Case Rep Neurol Med 2020;2020:1-5. https://doi.org/10.1155/2020/6810237.

[68] Garg D, Agarwal A, Dash D, Mahajan S, Singh RK, Bhatia R, et al. Rasmussen's encephalitis presenting as progressive parietal dysfunction sans seizures. Seizure 2019;71:219-21. https://doi.org/10.1016/j.seizure.2019.08.001.

[69] Orsini A, Costagliola G, Perna D, Esposito MG, Bonfiglio L, Striano P, et al. Efficacy and tolerability of mycophenolate mofetil in a pediatric Rasmussen syndrome. Epilepsy Behav Reports 2020;13:100334. https://doi.org/10.1016/J.EBR.2019.100334.

[70] Liossis SNC, Sfikakis PP. Rituximab-induced B cell depletion in autoimmune diseases: Potential effects on T cells. Clin Immunol 2008;127:280-5. https://doi.org/10.1016/j.clim.2008.01.011.

[71] El Tawil S, Morris R, Mullatti N, Nashef L, Rajakulendran S, S ET, et al. Adult onset Rasmussen's encephalitis associated with reflex language induced seizures responsive to Rituximab therapy. Seizure 2016;42:60-2.

https://doi.org/10.1016/j.seizure.2016.09.009.

[72] Laxer KD, Program PE, Pacific C, Francisco S. Pilot study of rituximab Tto treat chronic focal encephalitis. AES 2008, 2008, p. 9-10.

[73] Goyal M, Cohen ML, Bangert BA, Robinson S, Singer NG. Rasmussen syndrome and CNS granulomatous disease with NOD2/CARD15 mutations. Neurology 2007;69:6403. https://doi.org/10.1212/01.wnl.0000267429.89675.03.

[74] Vezzani A, Maroso M, Balosso S, Sanchez MA, Bartfai T. IL-1 receptor/Toll-like receptor signaling in infection, inflammation, stress and neurodegeneration couples hyperexcitability and seizures. Brain Behav Immun 2011;25:1281-9. https://doi.org/10.1016/j.bbi.2011.03.018.

[75] Dubé C, Vezzani A, Behrens M, Bartfai T, Baram TZ. Interleukin-1 $\beta$ contributes to the generation of experimental febrile seizures. Ann Neurol 2005;57:152-5. https://doi.org/10.1002/ana.20358.

[76] Vezzani A, Conti M, De Luigi A, Ravizza T, Moneta D, Marchesi F, et al. Interleukin-1 $\beta$ immunoreactivity and microglia are enhanced in the rat hippocampus by focal kainate application: Functional evidence for enhancement of electrographic seizures. J Neurosci 1999;19:5054-65. https://doi.org/10.1523/jneurosci.19-12-05054.1999.

[77] Iori V, Iyer AM, Ravizza T, Beltrame L, Paracchini L, Marchini S, et al. Blockade of the IL-1R1/TLR4 pathway mediates disease-modification therapeutic effects in a model of acquired epilepsy. Neurobiol Dis 2017;99:12-23. https://doi.org/10.1016/j.nbd.2016.12.007.

[78] Vezzani A, Moneta D, Conti M, Richichi C, Ravizza T, De Luigi A, et al. Powerful anticonvulsant action of IL-1 receptor antagonist on intracerebral injection and astrocytic overexpression in mice. Proc Natl Acad Sci U S A 2000;97:11534-9. https://doi.org/10.1073/pnas.190206797.

[79] Choi C ho, Ma S ho, Ma KK, Leung H, Mok VC. Super-refractory status epilepticus in autoimmune encephalitis treated with interleukin-1 receptor antagonist, anakinra. Epileptic Disord 2021;23:500-5. https://doi.org/10.1684/epd.2021.1283.

[80] Mochol M, Taubøll E, Sveberg L, Tennøe B, Berg Olsen K, Heuser K, et al. Seizure control after late introduction of anakinra in a patient with adult onset Rasmussen's encephalitis. Epilepsy Behav Reports 2021;16. 
https://doi.org/10.1016/j.ebr.2021.100462.

[81] Liba Z, Vaskova M, Zamecnik J, Kayserova J, Nohejlova H, Ebel M, et al. An immunotherapy effect analysis in Rasmussen encephalitis. BMC Neurol 2020;20:359. https://doi.org/10.1186/s12883-020-01932-9.

[82] Krauss GL, Campbell ML, Roche KW, Huganir RL, Niedermeyer E. Chronic steroidresponsive encephalitis without autoantibodies to glutamate receptor GluR3. Neurology 1996;46:247-9. https://doi.org/10.1212/WNL.46.1.247.

[83] McLachlan RS, Levin S, Blume WT. Treatment of Rasmussen's syndrome with ganciclovir. Neurology 1996;47:925-8. https://doi.org/10.1212/WNL.47.4.925.

[84] McLachlan RS, Diosy D, Levin S. Early treatment of a progressive rasmussen's like syndrome with ganciclovir. Can J Neurol Sci 2011;38:296-8. https://doi.org/10.1017/S0317167100011495.

[85] DeToledo JC, Smith DB. Partially Successful Treatment of Rasmussen's Encephalitis with Zidovudine: Symptomatic Improvement Followed by Involvement of the Contralateral Hemisphere. Epilepsia 1994;35:352-5. https://doi.org/10.1111/j.15281157.1994.tb02443.x.

[86] Bernard LM, Debbie MR, Mickle JP, Linda JS, Peter DR, Robin LG, et al. Intraventricular Alpha Interferon Therapy for Rasmussen's Syndrome. Can J Neurol Sci / J Can Des Sci Neurol 1993;20:333-6. https://doi.org/10.1017/S0317167100048277.

[87] Dabbagh O, Gascon G, Crowell J, Bamoggadam F. Intraventricular interferon- $\alpha$ stops seizures in Rasmussen's encephalitis: A case report. Epilepsia 1997;38:1045-9. https://doi.org/10.1111/j.1528-1157.1997.tb01491.x.

[88] Marjanovic BD, Stojanov LM, Zdravkovic DS, Kravljanac RM, Djordjevic MS. Rasmussen syndrome and long-term response to thalidomide. Pediatr Neurol 2003;29:151-6. https://doi.org/10.1016/S0887-8994(03)00216-9.

[89] Szczepanik E, Mierzewska H, Antczak-Marach D, Figiel-Dabrowska A, Terczynska I, Tryfon J, et al. Intrathecal Infusion of Autologous Adipose-Derived Regenerative Cells in Autoimmune Refractory Epilepsy: Evaluation of Safety and Efficacy. Stem Cells Int 2020;2020. https://doi.org/10.1155/2020/7104243. 


\section{FIGURES LEGENDS}

Figure 1: Putative main pathophysiological mechanisms observed in RE with the spectrum of actions of the most frequently used immunotherapies.

(Illustrations from smart.servier.com)

Figure 2: Illustration of the effect of immunotherapies in a mouse model of RE showing the ability of IV Immunoglobulins and $\alpha 4$ integrin blockage to reduced leucocytes infiltration and neuro-inflammation regardless the stage of the disease but demonstrating that solely early therapeutic intervention could have an impact on the epilepsy.

Figure 3: Illustration of the three phases of the RE and the different clinical forms of the disease; of the two distinct therapeutic windows for treatment by immunotherapies; and of the respective indications of immunotherapies and surgery. 
Figure 4: Summary of the efficacy of main studied immunotherapies, with more than 10 patients reported in the literature, in terms of seizure outcome (various criteria of response across studies). 